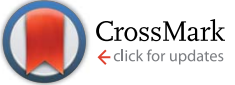

Cite this: RSC Adv., 2014, 4, 39809
Received 10th July 2014

Accepted 18th August 2014

DOI: $10.1039 / c 4 r a 08384 a$

www.rsc.org/advances

\section{3-Substituted biquinolinium inhibitors of AraC family transcriptional activator VirF from S. flexneri obtained through in situ chemical ionization of 3,4-disubstituted dihydroquinolines $\dagger$}

\author{
Prashi Jain, ${ }^{a}$ Jiaqin Li, ${ }^{b}$ Patrick Porubsky, ${ }^{a}$ Benjamin Neuenswander, ${ }^{c}$ Susan M. Egan, ${ }^{b}$ \\ Jeffrey Aubé acde and Steven Rogers ${ }^{\star d}$ \\ During a structure-activity relationship optimization campaign to develop an inhibitor of AraC family \\ transcriptional activators, we discovered an unexpected transformation of a previously reported inhibitor \\ that occurs under the assay conditions. Once placed in the assay media, the 3,4-disubstituted \\ dihydroquinoline core of the active analogue rapidly undergoes a decomposition reaction to a \\ quaternary 3-substituted biquinolinium. Further examination established an SAR for this chemotype while \\ also demonstrating its resilience to irreversible binding of biologically relevant nucleophiles.
}

\section{Introduction}

The World Health Organization (WHO) recently published a warning that microbial resistance to antibiotics has become a "major threat to public health". ${ }^{1}$ A dearth of new FDA approved antimicrobial medicines coupled with the rapid development of resistance to available antibiotics is creating a health care void that necessitates the development of new antimicrobial strategies to combat microbial infectious disease. ${ }^{2}$ One such strategy involves targeting non-growth essential virulence factors, which may avoid triggering resistance mechanism development by not placing selective pressure on microbes. As an example of this, the protein members of the AraC family of bacterial transcription activators activate expression of genes encoding virulence factors in various pathogenic bacteria such as Vibrio cholerae (ToxT), ${ }^{3}$ enterotoxigenic Escherichia coli (Rns/CfaD) (ETEC), ${ }^{4}$ Pseudomonas aeruginosa (ExsA) ${ }^{5}$ and Shigella flexneri (VirF), ${ }^{6}$ while other members of the family regulate bacterial stress responses or carbon metabolic operons. ${ }^{7}$ Furthermore,

${ }^{a}$ Center for Chemical Methodologies and Library Development, The University of Kansas, 2034 Becker Drive, Lawrence, Kansas, 66047, USA

${ }^{b}$ Department of Molecular Biosciences, University of Kansas, Lawrence, KS, USA

${ }^{c}$ Specialized Chemistry Center, The University of Kansas, 2034 Becker Drive, Lawrence, Kansas 66047, USA

${ }^{d}$ University of Kansas Center of Biomedical Research Excellence, Center for Cancer Experimental Therapeutics, 2034 Becker Drive, Lawrence, KS, USA. E-mail: sarogers@ku.edu

${ }^{e}$ Department of Medicinal Chemistry, University of Kansas, Lawrence, KS, USA

$\dagger$ Electronic supplementary information (ESI) available: Experimental protocols and structural characterization of target compounds. See DOI: $10.1039 / \mathrm{c} 4 \mathrm{ra} 08384 \mathrm{a}$

inhibition or deletion of AraC family activators has been demonstrated to ameliorate infections in vitro and in animal models. $^{8}$

Our study focuses on VirF, an AraC family transcriptional activator from Shigella flexneri, the causative agent of bacillary dysentery, or shigellosis. ${ }^{9}$ This disease affects over 165 million people worldwide while leading to approximately 1.1 million deaths annually. ${ }^{10}$ VirF is necessary for the expression of virulence genes associated with the first step of S. flexneri pathogenesis, which is rectal, and colonic epithelial cell invasion as well as the subsequent cell-to-cell dissemination. ${ }^{11}$ Using cellbased reporter gene assays with $S$. flexneri and E. coli, coupled with in vitro DNA-binding assays with purified VirF, we recently determined that SE-1 (Fig. 1) is an inhibitor of transcription activation and DNA binding by VirF. ${ }^{12}$ Furthermore, through examining mRNA concentrations using real-time quantitative reverse transcription-PCR (qRT-PCR), it was found that SE-1 reduced the expression of VirF-dependent virulence genes such as icsS, icsB, ipaB, and virB in S. flexneri. This initial study prompted us to seek analogues of SE-1 with greater potency that could serve as a lead VirF inhibitor.

In this manuscript, we detail our activity optimization efforts of SE-1, ${ }^{12}$ which was originally identified through screening of a

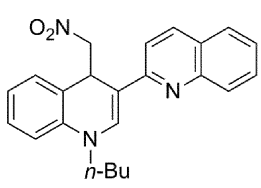

SE-1

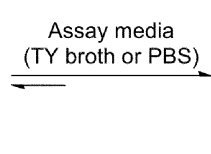

Fig. 1 In situ decomposition of SE-1 to biquinolinium 2. 
commercially obtained small molecule library, and show that SE-1 and related analogues undergo ionization in aqueous medium to afford a quaternary 3-substituted biquinolinium salt (Fig. 1). Although the decomposition product is a synthetic precursor to the 3,4-disubstituted dihydroquinoline core, its ionization in biological media was unexpected. Thus, we present evidence here that the biquinolinium salt is the causative agent responsible for the observed inhibitory activity toward bacterial AraC family activators, discuss structureactivity relationships (SARs) associated with this chemotype, and demonstrate that it is stable in the presence of biologically relevant nucleophiles.

\section{Results and discussion}

To gain preliminary SAR information to guide our synthetic endeavors, we procured and screened 24 commercially available analogues of SE-1, resulting in three compounds exhibiting notable activity in comparison to SE-1 in the VirF in vivo doseresponse assay in $E$. coli (Fig. 2). The assays were performed as previously described. ${ }^{\mathbf{1 2}}$ Briefly, the analogues were dissolved in $100 \%$ dimethyl sulfoxide (DMSO). Bacterial cultures were grown to an optical density at $600 \mathrm{~nm}\left(\mathrm{OD}_{600}\right)$ of $\sim 0.1$ and then mixed with various concentrations of analogues (final concentration of DMSO, 6.2\%), induced with $1 \mathrm{mM}$ IPTG (final concentration) for 3 hours at $37{ }^{\circ} \mathrm{C}$, lysed, and $\beta$-galactosidase activity was measured. Uninduced (no IPTG and no analogues) and uninhibited (1 mM IPTG and no analogues) controls were used to normalize $\beta$-galactosidase activity, as described previously. ${ }^{\mathbf{1 2}}$ To eliminate from consideration any analogues that nonspecifically inhibited $\beta$-galactosidase activity or cell growth, we also tested these analogues on a control strain that carried a lacZ reporter fusion (hts-lacz), with a synthetic promoter that was repressed by LacI and did not require VirF for activation, as described previously. ${ }^{\mathbf{1 2}}$ We found that analogues E1, A2 and C4 inhibited expression of the VirF-activated virB-lacZ fusion to the same extent as SE-1, with an $\mathrm{IC}_{50}$ of $7 \mu \mathrm{M}, 10 \mu \mathrm{M}$ and $11 \mu \mathrm{M}$ respectively. Other 4-substitutions were assessed such as an indole, a phenyl ring, a benzimidazole and a napthyl ring in which all analogues were found to be inactive (full list can be found in $\mathrm{ESI}_{\dagger} \dagger$ ). Analogues without N-substitution were also found to not exhibit activator inhibition.

To follow-up on our commercially accessible SAR, a series of 3,4-disubstituted dihydroquinolines were synthesized as shown in Scheme 1 that was adapted from protocols developed by Aksenov. ${ }^{13}$ We focused on the 4-methylnitro substitution instead of the malonic ester due to potential esterase liability and instead of the nitrile because E1 was found to be more
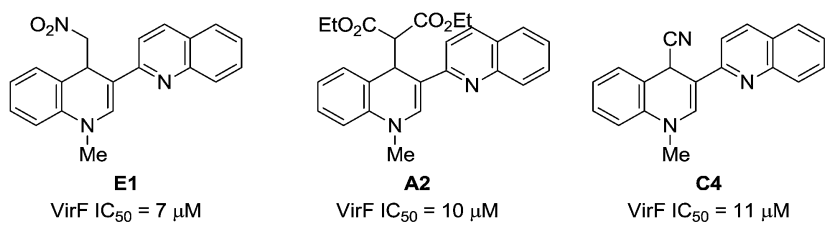

Fig. 2 Structures and VirF activator inhibition data for E1 and A2.

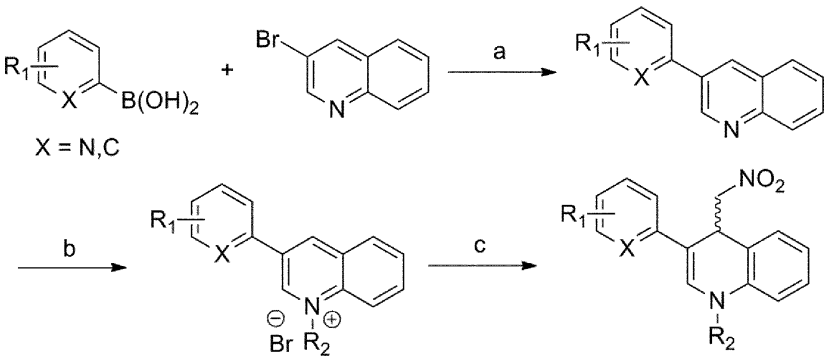

Scheme 1 Reagents and conditions: (a) $\mathrm{PdCl}_{2}\left(\mathrm{PPh}_{3}\right)_{2}, \mathrm{~K}_{2} \mathrm{CO}_{3}, \mathrm{DMF} /$ $\mathrm{H}_{2} \mathrm{O}, \mathrm{MW}, 150{ }^{\circ} \mathrm{C}$; (b) $\mathrm{R}_{2} \mathrm{Br}, \mathrm{MW}, 150{ }^{\circ} \mathrm{C}, 2 \mathrm{~h}$ (c) $\mathrm{MeNO}_{2}, \mathrm{~K}_{2} \mathrm{CO}_{3}, \mathrm{H}_{2} \mathrm{O}$, dioxane, rt, $4 \mathrm{~h}$.

active than C4. Briefly, various aryl boronic acids were coupled via Suzuki reaction with 3-bromoquinolines through the treatment with bis(triphenylphosphine)palladium dichloride, potassium carbonate in a $4: 1$ mixture of dimethylformamide and water while heating to $150{ }^{\circ} \mathrm{C}$ for 30 minutes under microwave conditions. The resulting 3 -substituted quinolines were subsequently $\mathrm{N}$-substituted via electrophilic attack from various benzyl and alkyl halides, followed by a nucleophilic attack at the 4-position of the resulting quinolinium halide through the treatment with nitromethane under basic conditions in dioxane at room temperature, giving the desired 3,4-disubstituted dihydroquinolines. Both the 3,4-disubstituted dihydroquinolines and quinolinium halide synthetic intermediates were screened for inhibitory activity against VirF.

Initially, seven 3,4-disubstituted dihydroquinolines, three quinolinium synthetic precursors and a new batch of SE-1 (1) were synthesized and screened for VirF activator inhibition (Table 1). Replacing the $n$-butyl group with a 4-chlorobenzyl (5) resulted in a significant loss of activity against VirF activator inhibition. Replacing the quinoline with other aryl groups such as 5-methyl pyridine (6), 3-chlorophenyl (7) resulted in analogues with very modest inhibitory activity, giving $\mathrm{IC}_{50}$ values $>100 \mu \mathrm{M}$. Diminished activity was also observed when substituting the nitromethyl of the 1,4-dihydroquinoline with a phenyl (8) or methyl (11) as well in the same substitution of a 1,2-dihydroquinolines (entries $9 \& 10$ ). However, the resynthesized SE-1 (Table 1) repeated the activity observed from the HTS sample with an $\mathrm{IC}_{50}$ of $11 \mu \mathrm{M}$ against VirF and $>100 \mu \mathrm{M}$ in the control strain.

As a first clue to the instability of these 1,4-dihydroquinoline cores, we observed that the quaternary amine quinolinium samples (Table 1, entries 2-4) exhibited the same, if not better activity against VirF while not affecting the control strain. This can be observed when comparing Table 1, entries 2 to SE-1 (1), entries 3 to 5 and entries 4 to E1. Furthermore, the 3,4-disubstituted dihydroquinolines (Table 1, SE-1 and entries 5-11) exhibited notable stability issues during their synthesis because they readily decomposed if purification attempts were made on normal phase chromatography with silica gel or reverse phase chromatography with C18-bonded silica gel. All 3,4-disubstituted dihydroquinolines had to be purified via recrystallization. We also noted that upon ${ }^{1} \mathrm{H}$ NMR analysis of various dihydroquinoline samples in $\mathrm{DMSO}-\mathrm{d}_{6}$ at room temperature two 
Table 1 First round of synthetic analogues

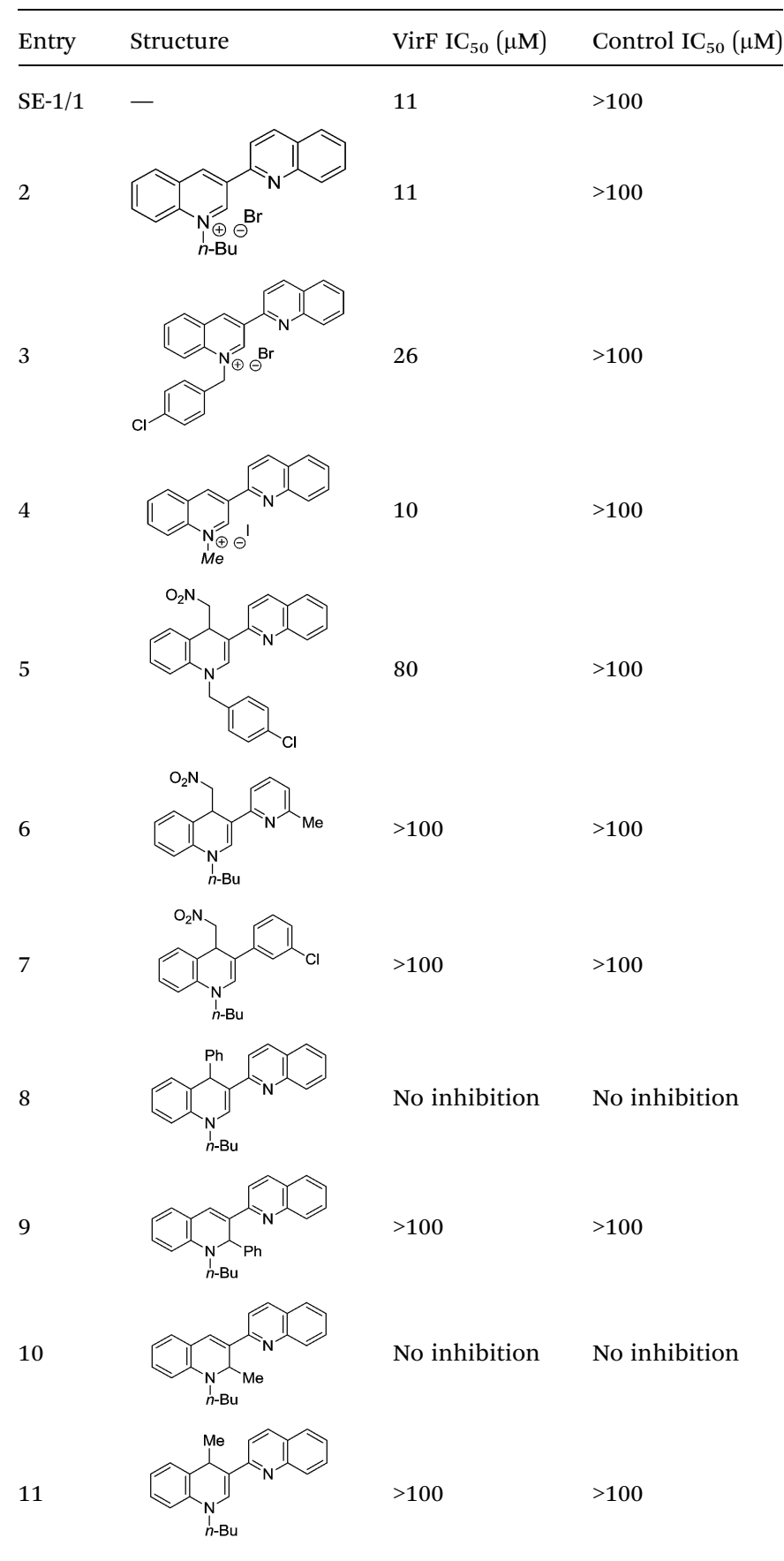

days after the samples had been prepared and analyzed, that a significant reversion to the quinolinium precursor was observed. These observations prompted us to examine (1) the latent instability of SE-1 and its analogues, (2) if the observed VirF inhibition activity was simply due to the quaternary species and (3) if non-quaternary adducts could be derived that demonstrated stability and VirF inhibitory activity.

To examine the aqueous stability of the 3,4-disubstituted dihydroquinoline analogues, samples were prepared at $10 \mu \mathrm{M}$ in PBS at pH 7.4 (1\% DMSO) and analyzed via auto-sampler by RP HPLC/UV/HRMS after the sample had been prepared and then every hour on the hour for 48 hours at room temperature. We found that SE-1 had degraded completely to the corresponding quaternary salt by the $0^{\text {th }}$ time point, or about 30 minutes elapsed time including assay preparation. Given that the VirF inhibition assays typically run 8-24 hours, the stability analysis predicted that no detectable concentration of the 3,4-disubstituted dihydroquinoline species was present during the assay and that the activity was simply due to the quinolinium salt. Since most quaternary ammonium salts have limited pharmaceutical relevance, save topical and oral hygiene applications due to their hemolytic nature, ${ }^{\mathbf{1 4}}$ we began exploring non-quaternary analogues of our most potent VirF activator inhibitors.

The 3,4-disubstituted dihydroquinoline core was substituted with an indole (Table 2, entries 12 and 13), 9-acridone (15) and 4-quinolone (16), resulting in no inhibitory activity towards VirF or in the control strain assay. Interestingly, we also screened acridinium (14), pyridinium (17) and triethylammonium (18) salt analogues that would behave similarly to other cationic quaternary ammonium chemical detergents such as cetylpyridinium chloride (CPC) to compare the activity profiles to our more active quinolinium compounds. The triethylammonium analogue exhibited no inhibitory activity in our assays whereas the acridinium and pyridinium exhibited good to modest, nonspecific activity against both the VirF and control strain, indicating that the activity we see with our quinolinium compounds is not simply due to detergent effects. This prompted us to continue optimizing the activity of the quinolinium core.

Various $\mathrm{N}$-substituted and 3-aryl analogues were synthesized with aim to optimize the quinolinium core (Table 2, entries 19$24)$. As seen previously, $N$-substitution of $n$-butyl with methyl (4) gave decreased activity with a $90 \mu \mathrm{M} \mathrm{IC}_{50}$ value, whereas $i$-propyl (19), n-propyl (20), $n$-hexyl (21) and pent-4-en-1-yl (24) all gave similar activity to SE-1 with $\mathrm{IC}_{50}$ values of $12 \mu \mathrm{M}, 16 \mu \mathrm{M}, 11 \mu \mathrm{M}$ and $11 \mu \mathrm{M}$ respectively, while not inhibiting the control strain. Replacing the 3-quinoline substituent with a naphthalene (23) was also well tolerated and gave an $\mathrm{IC}_{50}$ value of $9 \mu \mathrm{M}$ against VirF and $>100 \mu \mathrm{M}$ against the control strain, comparable activity to the parent compound (Table 1, entry 1). A modest increase in activity was attained while elongating the $N$-alkyl chain to $n$-nonyl (22); giving an $\mathrm{IC}_{50}$ value of $3 \mu \mathrm{M}$ against VirF, but notable selectivity was lost because of control strain inhibition with an $\mathrm{IC}_{50}$ value of $25 \mu \mathrm{M}$. A planktonic bacterial growth curve analysis of both the VirF and control strains in the presence of Table 1, entry 6 demonstrated that this compound inhibited the growth of the bacteria, explaining the increase in activity against both strains. This toxic effect on bacterial growth was not seen with the other active compounds.

Given the inherent electrophillic nature of cationic species such quinoliniums, we assessed the stability of some of these analogues towards the thiol based nucleophiles dithiothreitol and glutathione to mimic interactions with thiol containing amino acid residues of proteins in a biological system. Briefly, compounds were dissolved at $10 \mu \mathrm{M}$ in PBS at pH 7.4 (1\% DMSO) and incubated at room temperature with either no thiol source as a negative control, $50 \mu \mathrm{M}$ glutathione (GSH). The mixtures were sampled every hour for eight hours for 48 hours and analyzed by 
Table 2 Data

\begin{tabular}{llll}
\hline & & VirF & Control strain \\
Entry & Structure & $\mathrm{IC}_{50}(\mu \mathrm{M})$ & $\mathrm{IC}_{50}(\mu \mathrm{M})$ \\
\hline
\end{tabular}

12

13

14

15

16

18

19<smiles>CCCCn1cc(-c2ccc3ccccc3n2)c2ccccc21</smiles>

No activity No activity

No activity No activity

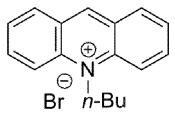<smiles>CCCCn1c2ccccc2c(=O)c2ccccc21</smiles>

No activity

No activity

No activity No activity

$>50$

No activity

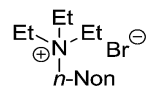<smiles></smiles>

12

$>100$

16<smiles></smiles><smiles></smiles>

11

$>100$

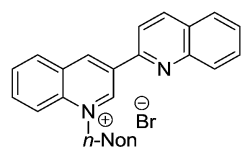

3

25

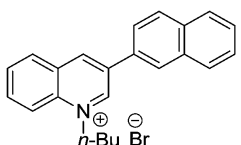

$>100$

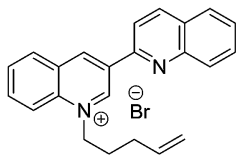

used as a positive control. In both of the quinolinium salts assayed (entries 2 and 3), no GSH adducts were observed, suggesting these compounds to be relatively stable despite their expected reactivity, giving this chemotype possible application toward developing biological probes while suggesting that these inhibitors may not be acting in a covalent manner.

\section{Conclusions}

Through analysis of SAR data and chemical stability behavior, we have discovered that our previously reported 3,4-disubstituted dihydroquinoline inhibitor of AraC transcription activators, ${ }^{12}$ readily fragments in assay media to a quinolinium core, which we ascribe as the active agent against this target. We note that SE-1 and analogues are available from several commercial vendors; and the present results suggest that the ionized precursors may well be responsible for any observed biological activity for this chemotype. Although we did not increase VirF activator inhibition potency of this class of compounds, we expounded the SAR and showed that the activity of the quinolinium analogues does depend on specific structure and was not due to generic detergent effects.

\section{Experimental section}

All air- and moisture-sensitive reactions were carried out in flame- or oven-dried glassware under argon atmosphere using standard gastight syringes, cannula, and septa. Stirring was achieved with oven-dried magnetic stir bars. Flash column chromatography was performed with $\mathrm{SiO}_{2}$ from Sorbent Technology (30930M-25, Silica Gel $60 \mathrm{~A}, 40-63 \mu \mathrm{m})$ or by using an automated chromatography instrument with an appropriately sized column. Thin layer chromatography was performed on silica gel w/UV254 plates (1624126, sorbent technologies). ${ }^{1} \mathrm{H}$ and ${ }^{13} \mathrm{C}$ NMR spectra were recorded on instruments operating at 400 or $500 \mathrm{MHz}$ and 100 or $126 \mathrm{MHz}$ respectively. Highresolution mass spectrometry (HRMS) spectra were obtained on an ESI-TOF mass spectrometer. The analytical method utilized a Waters Aquity BEH C18 column $(2.1 \times 50 \mathrm{~mm}, 1.7 \mu \mathrm{m})$ eluting with a linear gradient of $95 \%$ water (modified to $\mathrm{pH} 9.8$ through addition of $\mathrm{NH}_{4} \mathrm{OH}$ ) to $100 \% \mathrm{CH}_{3} \mathrm{CN}$ at $0.6 \mathrm{~mL} \mathrm{~min}^{-1}$ flow rate where purity was determined using UV peak area at $214 \mathrm{~nm}$. Melting points were determined using an automated apparatus with digital imaging capability.

\section{General procedure for 4-substituted biquinolines}

To a solution of nitromethane $(50 \mu \mathrm{L}, 1.0 \mathrm{mmol})$ in THF $(1 \mathrm{~mL})$, solution of $\mathrm{K}_{2} \mathrm{CO}_{3}(21.8 \mathrm{mg}, 0.15 \mathrm{mmol})$ in water $(0.2 \mathrm{~mL})$ was added gradually with stirring and the mixture was stirred for 5 min. The 3-(2-quinolyl)quinolinium halide (1a-e) $(0.75 \mathrm{mmol})$ was added and the mixture stirred for $4 \mathrm{~h}$ at $23{ }^{\circ} \mathrm{C}$ until a homogeneous solution was formed. The reaction was monitored by TLC/UPLC. The solution was poured into water $(5 \mathrm{~mL})$ and extracted with ethyl acetate $(3 \times 5 \mathrm{~mL})$. The organic layers were separated, combined, washed with brine, dried over

$\mathrm{Na}_{2} \mathrm{SO}_{4}$, and evaporated in vacuo.
RP HPLC/UV/HRMS. The masses of potential adducts were searched for in the final samples to determine if any detectable adduct formed. Ethacrynic acid, a known Michael acceptor, was 


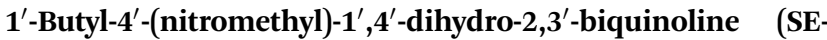
1). ${ }^{1} \mathrm{H}$ NMR (400 MHz, chloroform- $d$ ) $\delta 7.93(\mathrm{dd}, J=8.4,2.3 \mathrm{~Hz}$, $2 \mathrm{H}), 7.65(\mathrm{dd}, J=7.9,1.4 \mathrm{~Hz}, 1 \mathrm{H}), 7.58(\mathrm{ddd}, J=8.5,6.9,1.5 \mathrm{~Hz}$, $1 \mathrm{H}), 7.49(\mathrm{~d}, J=8.8 \mathrm{~Hz}, 1 \mathrm{H}), 7.34(\mathrm{ddd}, J=8.0,6.9,1.2 \mathrm{~Hz}, 1 \mathrm{H})$, $7.29(\mathrm{~s}, 1 \mathrm{H}), 7.24-7.21(\mathrm{~m}, 1 \mathrm{H}), 7.21-7.18(\mathrm{~m}, 1 \mathrm{H}), 6.96(\mathrm{td}, J=$ $7.4,1.0 \mathrm{~Hz}, 1 \mathrm{H}), 6.88(\mathrm{~d}, J=8.5 \mathrm{~Hz}, 1 \mathrm{H}), 5.39(\mathrm{dd}, J=8.2,4.1 \mathrm{~Hz}$, $1 \mathrm{H}), 4.70(\mathrm{dd}, J=10.9,4.1 \mathrm{~Hz}, 1 \mathrm{H}), 4.48(\mathrm{dd}, J=10.9,8.2 \mathrm{~Hz}$, $1 \mathrm{H}), 3.79(\mathrm{ddd}, J=14.4,8.5,5.9 \mathrm{~Hz}, 1 \mathrm{H}), 3.55(\mathrm{ddd}, J=14.9,8.5$, $6.8 \mathrm{~Hz}, 1 \mathrm{H}), 1.72(\mathrm{dqd}, J=15.9,7.8,6.0 \mathrm{~Hz}, 2 \mathrm{H}), 1.39(\mathrm{dtd}, J=$ 15.1, 7.7, $6.0 \mathrm{~Hz}, 2 \mathrm{H}), 0.94(\mathrm{t}, J=7.3 \mathrm{~Hz}, 3 \mathrm{H}) .{ }^{13} \mathrm{C}$ NMR (126 $\mathrm{MHz}$, acetone- $d 6) \delta 156.33,148.99,139.30,138.15,136.21$, 130.09, 129.54, 128.90, 128.33, 127.10, 125.71, 123.31, 122.68, 117.46, 113.46, 106.43, 80.95, 51.29, 38.84, 30.90, 20.66, 14.14. HRMS (ESI) $m / z$ calcd for $\mathrm{C}_{23} \mathrm{H}_{23} \mathrm{~N}_{3} \mathrm{O}_{2}[\mathrm{M}+\mathrm{H}]^{+}: 374.1824$, found: 374.1856 .

$1^{\prime}$-(4-Chlorobenzyl)-4' -(nitromethyl)-1', $4^{\prime}$-dihydro-2, $3^{\prime}$-biquinoline (5). ${ }^{1} \mathrm{H}$ NMR $(400 \mathrm{MHz}$, acetone- $d 6) \delta 8.16(\mathrm{~d}, J=9.0 \mathrm{~Hz}$, $1 \mathrm{H}), 8.02-7.96(\mathrm{~m}, 2 \mathrm{H}), 7.92(\mathrm{~d}, J=8.9 \mathrm{~Hz}, 1 \mathrm{H}), 7.85$ (dd, $J=7.9$, $1.4 \mathrm{~Hz}, 1 \mathrm{H}), 7.71$ (ddd, $J=8.5,6.9,1.5 \mathrm{~Hz}, 1 \mathrm{H}), 7.50-7.35(\mathrm{~m}$, $6 \mathrm{H}), 7.21-7.15(\mathrm{~m}, 1 \mathrm{H}), 7.04(\mathrm{td}, J=7.5,1.1 \mathrm{~Hz}, 1 \mathrm{H}), 6.95(\mathrm{~d}, J=$ 8.1 Hz, 1H), 5.56 (dd, $J=7.7,4.1 \mathrm{~Hz}, 1 \mathrm{H}), 5.26-5.08(\mathrm{~m}, 2 \mathrm{H}), 4.93$ $(\mathrm{dd}, J=11.0,4.1 \mathrm{~Hz}, 1 \mathrm{H}), 4.76(\mathrm{dd}, J=11.0,7.7 \mathrm{~Hz}, 1 \mathrm{H}) .{ }^{13} \mathrm{C}$ NMR (126 MHz, acetone- $d 6) \delta$ 156.24, 148.93, 139.33, 138.61, $137.70,136.35,133.42$, 130.18, 130.17, 129.63, 129.60, 129.24, $128.83,127.21,125.92,123.68,122.70,117.52,114.23,107.43$, 81.31, 54.57, 38.69. HRMS (ESI) $m / z$ calcd for $\mathrm{C}_{26} \mathrm{H}_{21} \mathrm{ClN}_{3} \mathrm{O}_{2}[\mathrm{M}+$ $\mathrm{H}]^{+}:$442.1244, found: 442.1288 .

$1^{\prime}$-Butyl-1' , $^{\prime}$-dihydro-[2,3'-biquinoline]-4'-carbonitrile (C1). ${ }^{1} \mathrm{H}$ NMR (400 MHz, acetone- $\left.d 6\right) \delta 8.17$ (d, $\left.J=8.7 \mathrm{~Hz}, 1 \mathrm{H}\right), 8.04-$ 7.97 (m, 1H), 7.92 (d, $J=8.9 \mathrm{~Hz}, 1 \mathrm{H}), 7.90$ (s, 1H), 7.86 (dd, $J=$ $8.1,1.5 \mathrm{~Hz}, 1 \mathrm{H}), 7.71$ (ddd, $J=8.5,6.9,1.5 \mathrm{~Hz}, 1 \mathrm{H}), 7.61$ (dd, $J=$ 7.6, $1.5 \mathrm{~Hz}, 1 \mathrm{H}$ ), 7.48 (ddd, $J=8.1,6.9,1.2 \mathrm{~Hz}, 1 \mathrm{H}), 7.40$ (ddd, $J$ $=8.6,7.3,1.6 \mathrm{~Hz}, 1 \mathrm{H}), 7.23(\mathrm{~d}, J=7.6 \mathrm{~Hz}, 1 \mathrm{H}), 7.16(\mathrm{td}, J=7.5$, $1.1 \mathrm{~Hz}, 1 \mathrm{H}), 5.92(\mathrm{~s}, 1 \mathrm{H}), 4.12-4.00(\mathrm{~m}, 1 \mathrm{H}), 3.91$ (ddd, $J=14.9$, 8.3, $6.9 \mathrm{~Hz}, 1 \mathrm{H}), 1.86-1.74(\mathrm{~m}, 2 \mathrm{H}), 1.52(\mathrm{dtd}, J=11.9,7.3,3.4$ $\mathrm{Hz}, 2 \mathrm{H}), 1.01(\mathrm{t}, J=7.4 \mathrm{~Hz}, 3 \mathrm{H}) .{ }^{13} \mathrm{C}$ NMR (100 MHz, acetone- $\left.d 6\right)$ $\delta$ 155.52, 148.85, 138.62, 137.63, 136.38, 131.21, 130.21, 129.99, 129.55, 128.41, 127.19, 125.96, 123.86, 121.63, 118.39, 117.09, 114.50, 103.64, 51.50, 30.99, 30.50, 20.52, 14.10. HRMS (ESI) $m / z$ calcd for $\mathrm{C}_{23} \mathrm{H}_{22} \mathrm{~N}_{3}[\mathrm{M}+\mathrm{H}]^{+}$: 340.1808, found: 340.1807 .

1-Butyl-3-(6-methylpyridin-2-yl)-4-(nitromethyl)-1,4-dihydroquinoline (6). ${ }^{1} \mathrm{H}$ NMR $(400 \mathrm{MHz}$, acetone- $d 6) \delta 7.42(\mathrm{~s}, 1 \mathrm{H})$, $7.39(\mathrm{~d}, J=7.7 \mathrm{~Hz}, 1 \mathrm{H}), 7.27(\mathrm{~d}, J=8.1 \mathrm{~Hz}, 1 \mathrm{H}), 7.15-7.04(\mathrm{~m}, 2 \mathrm{H})$, $6.96(\mathrm{~d}, J=8.1 \mathrm{~Hz}, 1 \mathrm{H}), 6.84(\mathrm{dd}, J=7.4,1.1 \mathrm{~Hz}, 1 \mathrm{H}), 6.80(\mathrm{~d}, J=$ $7.6 \mathrm{~Hz}, 1 \mathrm{H}), 5.04(\mathrm{dd}, J=8.6,4.2 \mathrm{~Hz}, 1 \mathrm{H}), 4.61(\mathrm{dd}, J=10.9,4.1$ $\mathrm{Hz}, 1 \mathrm{H}), 4.29(\mathrm{dd}, J=10.9,8.6 \mathrm{~Hz}, 1 \mathrm{H}), 3.82(\mathrm{ddd}, J=14.2,8.0,5.8$ Hz, 1H), 3.59 (ddd, $J=14.9,8.3,6.9 \mathrm{~Hz}, 1 \mathrm{H}$ ), 2.35 (s, 3H), 1.68$1.52(\mathrm{~m}, 2 \mathrm{H}), 1.38-1.26(\mathrm{~m}, 2 \mathrm{H}), 0.85$ (t, $J=7.4 \mathrm{~Hz}, 3 \mathrm{H}) .{ }^{13} \mathrm{C} \mathrm{NMR}$ (126 MHz, acetone- $d 6$ ) $\delta$ 158.09, 155.89, 150.29, 139.59, 138.35, $137.19,135.90,133.94,130.59,130.03,129.55,128.82,127.80$, $123.21,122.83,122.27,119.55,118.60,114.62,113.16,105.69$, 80.68, 51.02, 39.21, 30.90, 24.76, 20.66, 14.13. HRMS (ESI) $\mathrm{m} / \mathrm{z}$ calcd for $\mathrm{C}_{20} \mathrm{H}_{24} \mathrm{~N}_{3} \mathrm{O}_{2}[\mathrm{M}+\mathrm{H}]^{+}$: 338.1863, found: 338.1855 .

1-Butyl-3-(3-chlorophenyl)-4-(nitromethyl)-1,4-dihydroquinoline (7). ${ }^{1} \mathrm{H}$ NMR (400 MHz, acetone- $\left.d 6\right) \delta 7.45(\mathrm{t}, J=2.0 \mathrm{~Hz}, 1 \mathrm{H})$, $7.38(\mathrm{ddd}, J=8.0,2.0,1.0 \mathrm{~Hz}, 1 \mathrm{H}), 7.21$ (t, $J=8.0 \mathrm{~Hz}, 1 \mathrm{H}), 7.19-$ $7.09(\mathrm{~m}, 2 \mathrm{H}), 7.07-6.99(\mathrm{~m}, 2 \mathrm{H}), 6.96(\mathrm{~d}, J=8.0 \mathrm{~Hz}, 1 \mathrm{H}), 6.83$ (td, $J=7.4,1.1 \mathrm{~Hz}, 1 \mathrm{H}), 4.80(\mathrm{dd}, J=8.9,4.1 \mathrm{~Hz}, 1 \mathrm{H}), 4.42$ (dd, $J=11.4,4.1 \mathrm{~Hz}, 1 \mathrm{H}), 4.20(\mathrm{dd}, J=11.4,8.9 \mathrm{~Hz}, 1 \mathrm{H}), 3.81$ (ddd, $J=14.3,8.2,5.8 \mathrm{~Hz}, 1 \mathrm{H}), 3.61$ (ddd, $J=14.8,8.4,6.8 \mathrm{~Hz}, 1 \mathrm{H}$ ), 1.68-1.57 (m, 2H), 1.39-1.26 (m, 2H), 0.85 (t, $J=7.4 \mathrm{~Hz}, 3 \mathrm{H}) .{ }^{13} \mathrm{C}$ NMR (126 MHz, acetone- $d 6) \delta 141.05,139.52,135.22,134.30$, $131.15,129.85,129.02,125.70,123.92$, 122.65, 122.43, 121.45, 113.04, 103.73, 79.85, 50.82, 40.44, 30.88, 20.69, 14.13. HRMS (ESI) $m / z$ calcd for $\mathrm{C}_{20} \mathrm{H}_{22} \mathrm{ClN}_{2} \mathrm{O}_{2}{ }^{+}[\mathrm{M}+\mathrm{H}]^{+}: 357.1364$, found: 357.1369 .

\section{Series of quaternary quinolinium salts}

$1^{\prime}$-Butyl-[2,3'-biquinolin]-1'-ium bromide (2). ${ }^{1} \mathrm{H}$ NMR (400 MHz, chloroform- $d$ ) $\delta 11.33(\mathrm{~d}, J=1.9 \mathrm{~Hz}, 1 \mathrm{H}), 10.20(\mathrm{~s}, 0 \mathrm{H})$, $9.15(\mathrm{~d}, J=8.6 \mathrm{~Hz}, 1 \mathrm{H}), 8.57(\mathrm{dd}, J=8.2,1.4 \mathrm{~Hz}, 1 \mathrm{H}), 8.46(\mathrm{~d}, J=$ $8.6 \mathrm{~Hz}, 1 \mathrm{H}), 8.32$ (d, $J=8.9 \mathrm{~Hz}, 1 \mathrm{H}), 8.25-8.13(\mathrm{~m}, 2 \mathrm{H}), 7.97$ (ddd, $J=8.1,7.0,0.9 \mathrm{~Hz}, 1 \mathrm{H}), 7.90$ (d, $J=6.7 \mathrm{~Hz}, 0 \mathrm{H}), 7.81$ (ddd, $J=8.5,6.8,1.4 \mathrm{~Hz}, 1 \mathrm{H}), 7.63(\mathrm{ddd}, J=8.1,6.8,1.2 \mathrm{~Hz}, 1 \mathrm{H}), 5.68$ $(\mathrm{t}, J=7.6 \mathrm{~Hz}, 2 \mathrm{H}), 2.24-2.12(\mathrm{~m}, 2 \mathrm{H}), 1.74-1.64(\mathrm{~m}, 2 \mathrm{H}), 1.06(\mathrm{t}, J$ $=7.3 \mathrm{~Hz}, 3 \mathrm{H}) .{ }^{13} \mathrm{C}$ NMR (126 MHz, DMSO) $\delta 150.59,148.87$, 147.35 , 144.11, 138.34, 137.17, 136.10, 132.31, 131.52, 130.91, 130.35, 129.65, 129.08, 128.17, 127.86, 127.65, 119.07, 118.87, $57.68,31.69,19.24,13.50$. HRMS (ESI) $\mathrm{m} / z$ calcd for $\mathrm{C}_{22} \mathrm{H}_{21} \mathrm{~N}_{2}{ }^{+}$ $[\mathrm{M}]^{+}:$313.1699, found: 313.1695.

$\mathbf{1}^{\prime}$-(4-Chlorobenzyl)-[2,3'-biquinolin]-1'-ium bromide (3). ${ }^{1} \mathrm{H}$ NMR (400 MHz, DMSO-d6) $\delta 10.67$ (d, $J=2.1 \mathrm{~Hz}, 1 \mathrm{H}), 10.24(\mathrm{~s}$, $1 \mathrm{H}), 8.79(\mathrm{~d}, J=8.6 \mathrm{~Hz}, 1 \mathrm{H}), 8.67$ (d, $J=7.8 \mathrm{~Hz}, 1 \mathrm{H}), 8.58(\mathrm{~d}, J=$ $8.6 \mathrm{~Hz}, 1 \mathrm{H}), 8.49(\mathrm{~d}, J=8.9 \mathrm{~Hz}, 1 \mathrm{H}), 8.30-8.20(\mathrm{~m}, 2 \mathrm{H}), 8.16(\mathrm{~d}, J$ $=8.1 \mathrm{~Hz}, 1 \mathrm{H}), 8.10(\mathrm{t}, J=7.6 \mathrm{~Hz}, 1 \mathrm{H}), 7.95(\mathrm{ddd}, J=8.4,6.8,1.5$ $\mathrm{Hz}, 1 \mathrm{H}), 7.77$ (t, $J=7.6 \mathrm{~Hz}, 1 \mathrm{H}), 7.62-7.43(\mathrm{~m}, 3 \mathrm{H}), 6.60(\mathrm{~s}, 2 \mathrm{H})$. ${ }^{13} \mathrm{C}$ NMR (126 MHz, DMSO) $\delta$ 150.58, 150.05, 147.32, 144.94, 138.36, 137.18, 136.21, 133.39, 132.98, 132.64, 131.66, 130.94, 130.46, 129.86, 129.31, 129.06, 129.00, 128.19, 127.90, 127.69, 119.34, 118.93, 59.79. HRMS (ESI) $\mathrm{m} / z$ calcd for $\mathrm{C}_{25} \mathrm{H}_{18} \mathrm{ClN}_{2}{ }^{+}$ $[\mathrm{M}]^{+}:$381.1153, found: 381.1158 .

$\mathbf{1}^{\prime}$-Methyl-[2,3'-biquinolin]-1'-ium iodide (4). Obtained as a yellow solid. ${ }^{1} \mathrm{H}$ NMR (400 MHz, DMSO- $\left.d 6\right) \delta 10.40(\mathrm{~s}, 1 \mathrm{H}), 10.12$ $(\mathrm{s}, 1 \mathrm{H}), 8.76(\mathrm{~d}, J=8.6 \mathrm{~Hz}, 1 \mathrm{H}), 8.62(\mathrm{dd}, J=12.2,8.4 \mathrm{~Hz}, 2 \mathrm{H})$, $8.52(\mathrm{~d}, J=8.8 \mathrm{~Hz}, 1 \mathrm{H}), 8.36$ (ddd, $J=8.7,7.0,1.6 \mathrm{~Hz}, 1 \mathrm{H}), 8.24$ $(\mathrm{d}, J=8.5 \mathrm{~Hz}, 1 \mathrm{H}), 8.15(\mathrm{dt}, J=7.8,3.6 \mathrm{~Hz}, 2 \mathrm{H}), 7.95$ (ddd, $J=$ 8.6, 6.8, 1.6 Hz, 1H), 7.76 (t, $J=7.5 \mathrm{~Hz}, 1 \mathrm{H}), 4.83$ (s, 3H). HRMS (ESI) $\mathrm{m} / z$ calcd for $\mathrm{C}_{19} \mathrm{H}_{15} \mathrm{~N}_{2}^{+}[\mathrm{M}]^{+}: 271.1230$, found: 271.1226 .

1-Nonylpyridin-1-ium bromide (17). ${ }^{1} \mathrm{H}$ NMR $(500 \mathrm{MHz}$, chloroform- $d$ ) $\delta 9.53(\mathrm{~d}, J=5.6 \mathrm{~Hz}, 2 \mathrm{H}), 8.54(\mathrm{t}, J=7.8 \mathrm{~Hz}, 1 \mathrm{H})$, 8.24-8.07 (m, 2H), $5.02(\mathrm{t}, J=7.5 \mathrm{~Hz}, 2 \mathrm{H}), 2.05(\mathrm{p}, J=7.5 \mathrm{~Hz}$, $2 \mathrm{H}), 1.41-1.17(\mathrm{~m}, 12 \mathrm{H}), 0.86(\mathrm{t}, J=7.0 \mathrm{~Hz}, 3 \mathrm{H}) .{ }^{13} \mathrm{C} \mathrm{NMR}$ (126 MHz, CDCl3) $\delta 145.16,145.12,128.46,62.17,32.06,31.76$, 29.29, 29.14, 29.06, 26.06, 22.61, 14.10. HRMS (ESI) $\mathrm{m} / \mathrm{z}$ calcd for $\mathrm{C}_{14} \mathrm{H}_{24} \mathrm{~N}^{+}[\mathrm{M}]^{+}$: 206.1903, found: 206.1921.

$\boldsymbol{N}, \boldsymbol{N}, \boldsymbol{N}$-Triethylnonan-1-aminium bromide (18). ${ }^{1} \mathrm{H} \quad \mathrm{NMR}$ (400 MHz, DMSO-d6) $\delta 3.23$ (q, $J=7.2 \mathrm{~Hz}, 6 \mathrm{H}$ ), 3.11 (dd, $J=7.8$, $4.1 \mathrm{~Hz}, 2 \mathrm{H}), 1.65-1.49$ (m, 2H), 1.34-1.23 (m, 12H), 1.20-1.14 $(\mathrm{m}, 9 \mathrm{H}), 0.92-0.81(\mathrm{~m}, 3 \mathrm{H}) .{ }^{13} \mathrm{C} \mathrm{NMR}(126 \mathrm{MHz}, \mathrm{DMSO}) \delta 55.94$, 51.89, 45.65, 38.79, 38.66, 31.20, 28.76, 28.48, 25.76, 22.05, 20.87, 13.93, 7.12. HRMS (ESI) $m / z$ calcd for $\mathrm{C}_{15} \mathrm{H}_{34} \mathrm{~N}^{+}[\mathrm{M}]^{+}$: 228.2686, found: 228.2708 . 
$1^{\prime}$-Isopropyl-[2,3'-biquinolin]-1'-ium iodide (19). ${ }^{1} \mathrm{H}$ NMR (400 MHz, DMSO- $d 6) \delta 10.19(\mathrm{~d}, J=1.9 \mathrm{~Hz}, 1 \mathrm{H}), 10.12(\mathrm{~d}, J=1.7$ $\mathrm{Hz}, 1 \mathrm{H}), 8.82$ (d, $J=9.3 \mathrm{~Hz}, 1 \mathrm{H}), 8.76$ (d, $J=8.6 \mathrm{~Hz}, 1 \mathrm{H}), 8.66$ (dd, $J=8.3,1.5 \mathrm{~Hz}, 1 \mathrm{H}), 8.58$ (d, $J=8.6 \mathrm{~Hz}, 1 \mathrm{H}), 8.36$ (ddd, $J=$ 8.8, 7.1, $1.6 \mathrm{~Hz}, 1 \mathrm{H}), 8.27$ (d, $J=8.5 \mathrm{~Hz}, 1 \mathrm{H}), 8.19-8.10(\mathrm{~m}, 3 \mathrm{H})$, $7.94(\mathrm{ddd}, J=8.4,6.9,1.5 \mathrm{~Hz}, 1 \mathrm{H}), 7.76$ (ddd, $J=8.1,6.8,1.2 \mathrm{~Hz}$, 1H), 6.08-5.95 (m, 1H), 1.89 (d, $J=6.5 \mathrm{~Hz}, 6 \mathrm{H}) .{ }^{13} \mathrm{C}$ NMR (126 MHz, DMSO) $\delta 150.64,147.30,144.00,138.30,136.11,132.32$, $131.74,130.84,130.25,129.73,129.25,128.67,128.11,127.87$, 127.67, 119.03, 118.70, 21.94. HRMS (ESI) $\mathrm{m} / \mathrm{z}$ calcd for $\mathrm{C}_{21} \mathrm{H}_{19} \mathrm{~N}_{2}^{+}[\mathrm{M}]^{+}$: 299.1543, found: 299.1542 .

1'-Propyl-[2,3'-biquinolin]-1'-ium bromide (20). ${ }^{1} \mathrm{H}$ NMR (400 MHz, DMSO-d6) $\delta 10.42$ (d, $J=2.0 \mathrm{~Hz}, 1 \mathrm{H}), 10.14(\mathrm{~s}, 1 \mathrm{H}), 8.77$ (d, $J=8.7 \mathrm{~Hz}, 1 \mathrm{H}), 8.73(\mathrm{~d}, J=8.9 \mathrm{~Hz}, 1 \mathrm{H}), 8.66(\mathrm{~d}, J=7.1 \mathrm{~Hz}, 1 \mathrm{H})$, $8.53(\mathrm{~d}, J=8.7 \mathrm{~Hz}, 1 \mathrm{H}), 8.34$ (ddd, $J=8.6,6.9,1.5 \mathrm{~Hz}, 1 \mathrm{H}), 8.25$ $(\mathrm{d}, J=8.4 \mathrm{~Hz}, 1 \mathrm{H}), 8.14(\mathrm{t}, J=8.0 \mathrm{~Hz}, 2 \mathrm{H}), 7.94(\mathrm{ddd}, J=8.5,6.9$, $1.5 \mathrm{~Hz}, 1 \mathrm{H}), 7.76(\mathrm{t}, J=7.8 \mathrm{~Hz}, 1 \mathrm{H}), 5.23(\mathrm{t}, J=7.7 \mathrm{~Hz}, 2 \mathrm{H}), 2.12$ $(\mathrm{h}, J=7.4 \mathrm{~Hz}, 2 \mathrm{H}), 1.09(\mathrm{t}, J=7.3 \mathrm{~Hz}, 3 \mathrm{H}) .{ }^{13} \mathrm{C} \mathrm{NMR}(126 \mathrm{MHz}$, DMSO) $\delta 150.60,148.90,147.35,144.14,138.35,137.20,136.07$, 132.27, 131.51, 130.91, 130.36, 129.63, 129.08, 128.17, 127.86, 127.66, 119.10, 118.87, 59.03, 23.17, 10.63. HRMS (ESI) $\mathrm{m} / \mathrm{z}$ calcd for $\mathrm{C}_{21} \mathrm{H}_{19} \mathrm{~N}_{2}^{+}[\mathrm{M}]^{+}$: 299.1543, found: 299.1542.

$\mathbf{1}^{\prime}$-Hexyl-[2,3'-biquinolin]-1'-ium bromide (21). ${ }^{1} \mathrm{H}$ NMR (500 MHz, DMSO- $d 6) \delta 10.41(\mathrm{~d}, J=2.0 \mathrm{~Hz}, 1 \mathrm{H}), 10.12(\mathrm{~s}, 0 \mathrm{H}), 8.76(\mathrm{~d}$, $J=8.6 \mathrm{~Hz}, 1 \mathrm{H}), 8.70(\mathrm{~d}, J=9.0 \mathrm{~Hz}, 1 \mathrm{H}), 8.65(\mathrm{~d}, J=8.0 \mathrm{~Hz}, 1 \mathrm{H})$, $8.52(\mathrm{~d}, J=8.6 \mathrm{~Hz}, 1 \mathrm{H}), 8.34$ (ddd, $J=8.8,7.0,1.5 \mathrm{~Hz}, 1 \mathrm{H}), 8.24$ $(\mathrm{d}, J=8.4 \mathrm{~Hz}, 1 \mathrm{H}), 8.18-8.09(\mathrm{~m}, 2 \mathrm{H}), 7.94$ (ddd, $J=8.4,6.8,1.5$ $\mathrm{Hz}, 1 \mathrm{H}$ ), 7.76 (ddd, $J=8.0,6.7,1.2 \mathrm{~Hz}, 1 \mathrm{H}), 5.25$ (t, $J=7.9 \mathrm{~Hz}$, $2 \mathrm{H}), 2.07$ (p, $J=7.6 \mathrm{~Hz}, 2 \mathrm{H}), 1.53$ (p, $J=7.3 \mathrm{~Hz}, 2 \mathrm{H}), 1.42-1.27$ $(\mathrm{m}, 6 \mathrm{H}), 0.90(\mathrm{t}, J=6.9 \mathrm{~Hz}, 3 \mathrm{H}) .{ }^{13} \mathrm{C}$ NMR (126 MHz, DMSO) $\delta$ 150.60, 148.90, 147.36, 144.11, 138.35, 137.16, 136.11, 132.31, 131.52, 130.92, 130.35, 129.64, 129.07, 128.18, 127.87, 127.66, 119.07, 118.88, 57.83, 30.71, 29.70, 25.46, 21.95, 13.86. HRMS (ESI) $m / z$ calcd for $\mathrm{C}_{24} \mathrm{H}_{25} \mathrm{~N}_{2}^{+}[\mathrm{M}]^{+}: 341.2012$, found: 341.2013 .

$\mathbf{1}^{\prime}$-Nonyl-[2,3'-biquinolin]-1'-ium bromide (22). ${ }^{1} \mathrm{H}$ NMR $(400$ MHz, DMSO- $d 6) \delta 10.42(\mathrm{~d}, J=1.8 \mathrm{~Hz}, 1 \mathrm{H}), 10.14-10.11$ (d, $J=$ $1.54 \mathrm{~Hz}, 1 \mathrm{H}), 8.77$ (d, $J=8.6 \mathrm{~Hz}, 1 \mathrm{H}), 8.70(\mathrm{~d}, J=9.0 \mathrm{~Hz}, 1 \mathrm{H}), 8.66$ $(\mathrm{d}, J=8.3 \mathrm{~Hz}, 1 \mathrm{H}), 8.53(\mathrm{~d}, J=8.7 \mathrm{~Hz}, 1 \mathrm{H}), 8.34(\mathrm{ddd}, J=8.7,7.0$, $1.4 \mathrm{~Hz}, 1 \mathrm{H}), 8.24(\mathrm{~d}, J=8.5 \mathrm{~Hz}, 1 \mathrm{H}), 8.14(\mathrm{t}, J=8.2 \mathrm{~Hz}, 2 \mathrm{H}), 7.94$ (ddd, $J=8.4,6.9,1.4 \mathrm{~Hz}, 1 \mathrm{H}), 7.76(\mathrm{ddd}, J=8.1,7.0,1.1 \mathrm{~Hz}, 1 \mathrm{H})$, $5.26(\mathrm{t}, J=7.8 \mathrm{~Hz}, 2 \mathrm{H}), 2.08(\mathrm{p}, J=9.5,8.6 \mathrm{~Hz}, 2 \mathrm{H}), 1.51(\mathrm{tt}, J=$ 9.7, $5.3 \mathrm{~Hz}, 2 \mathrm{H}), 1.35-1.39(\mathrm{~m}, 2 \mathrm{H}) 1.32-1.18(\mathrm{~m}, 6 \mathrm{H}), 0.85(\mathrm{t}, J=$ $7.1 \mathrm{~Hz}, 3 \mathrm{H}) .{ }^{13} \mathrm{C}$ NMR (126 MHz, DMSO) $\delta 150.59,148.88,147.35$, 144.09 , 138.34, 137.15, 136.09, 132.29, 131.51, 130.90, 130.34, 129.63, 129.06, 128.17, 127.86, 127.65, 119.08, 118.88, 57.81, $31.20,29.70,28.82,28.52,25.77,22.04,13.91$. HRMS (ESI) $\mathrm{m} / \mathrm{z}$ calcd for $\mathrm{C}_{27} \mathrm{H}_{31} \mathrm{~N}_{2}^{+}[\mathrm{M}]^{+}$: 383.2482, found: 383.2464 .

1-Butyl-3-(naphthalen-2-yl)quinolin-1-ium bromide (23). ${ }^{1} \mathrm{H}$ NMR (500 MHz, DMSO-d6) $\delta 10.18(\mathrm{~d}, J=2.1 \mathrm{~Hz}, 1 \mathrm{H}), 9.80(\mathrm{~d}, J$ $=1.9 \mathrm{~Hz}, 1 \mathrm{H}), 8.66(\mathrm{t}, J=4.5 \mathrm{~Hz}, 2 \mathrm{H}), 8.54(\mathrm{~d}, J=6.6 \mathrm{~Hz}, 0 \mathrm{H})$, 8.29 (ddd, $J=8.8,7.0,1.5 \mathrm{~Hz}, 1 \mathrm{H}), 8.24$ (d, $J=8.7 \mathrm{~Hz}, 1 \mathrm{H}), 8.19$ (dd, $J=8.5,1.9 \mathrm{~Hz}, 1 \mathrm{H}), 8.14-8.03(\mathrm{~m}, 3 \mathrm{H}), 7.73-7.63(\mathrm{~m}, 2 \mathrm{H})$, $5.19(\mathrm{t}, J=7.8 \mathrm{~Hz}, 2 \mathrm{H}), 2.07$ (p, $J=7.7 \mathrm{~Hz}, 1 \mathrm{H}), 1.53$ (h, $J=7.4$ $\mathrm{Hz}, 2 \mathrm{H}), 0.99$ (t, $J=7.3 \mathrm{~Hz}, 3 \mathrm{H}) .{ }^{13} \mathrm{C}$ NMR (126 MHz, DMSO) $\delta$ 148.82, 143.37, 136.27, 135.36, 133.52, 133.09, 132.98, 130.93, $130.80,130.20,129.82,129.26,128.38,127.80,127.54,127.28$,
127.07, 124.51, 118.86, 57.53, 31.69, 19.30, 13.51. HRMS (ESI) m/ $z$ calcd for $\mathrm{C}_{23} \mathrm{H}_{22} \mathrm{~N}^{+}[\mathrm{M}]^{+}$: 312.1747, found: 312.1754 .

$1^{\prime}$-(Pent-4-en-1-yl)-[2,3'-biquinolin]-1'-ium bromide (24). Obtained as a offwhite solid. ${ }^{1} \mathrm{H}$ NMR (400 MHz, DMSO- $\left.d 6\right) \delta$ 10.41 (d, $J=2.0 \mathrm{~Hz}, 1 \mathrm{H}), 10.17-10.11(\mathrm{~m}, 1 \mathrm{H}), 8.77$ (d, $J=8.7 \mathrm{~Hz}$, $1 \mathrm{H}), 8.68$ (dd, $J=16.9,8.6 \mathrm{~Hz}, 2 \mathrm{H}), 8.53(\mathrm{~d}, J=8.6 \mathrm{~Hz}, 1 \mathrm{H}), 8.35$ $(\mathrm{t}, J=7.8 \mathrm{~Hz}, 1 \mathrm{H}), 8.25(\mathrm{~d}, J=8.3 \mathrm{~Hz}, 1 \mathrm{H}), 8.14(\mathrm{t}, J=7.7 \mathrm{~Hz}$, $3 \mathrm{H}), 7.95(\mathrm{t}, J=7.3 \mathrm{~Hz}, 1 \mathrm{H}), 7.77(\mathrm{dd}, J=8.3,6.9 \mathrm{~Hz}, 1 \mathrm{H}), 6.05-$ $5.78(\mathrm{~m}, 1 \mathrm{H}), 5.27(\mathrm{~d}, J=7.6 \mathrm{~Hz}, 2 \mathrm{H}), 5.18-5.09(\mathrm{~m}, 1 \mathrm{H}), 5.06(\mathrm{~d}, J$ $=10.8 \mathrm{~Hz}, 1 \mathrm{H}), 2.35-2.28(\mathrm{~m}, 2 \mathrm{H}), 2.25-2.14(\mathrm{~m}, 2 \mathrm{H}) .{ }^{13} \mathrm{C} \mathrm{NMR}$ (126 MHz, DMSO) $\delta$ 150.58, 149.21, 149.08, 147.35, 144.16, $138.35,137.65,137.18,137.10,136.13,132.28,131.54,130.92$, 130.36, 129.65, 129.10, 128.17, 127.95, 119.04, 118.85, 115.87, 57.46, 29.89, 28.52. HRMS (ESI) $m / z$ calcd for $\mathrm{C}_{23} \mathrm{H}_{21} \mathrm{~N}_{2}{ }^{+}[\mathrm{M}]^{+}$: 325.1699, found: 325.1696 .

\section{Miscellaneous scaffolds}

$\mathbf{1}^{\prime}$-Butyl-4' -phenyl-1', $4^{\prime}$-dihydro-2, $3^{\prime}$-biquinoline $\quad(8) \cdot{ }^{15} \quad{ }^{1} \mathrm{H}$ NMR (400 MHz, acetone- $d 6) \delta 8.22$ (d, $J=8.7 \mathrm{~Hz}, 1 \mathrm{H}), 8.07$ (dd, $J$ $=8.3,1.0 \mathrm{~Hz}, 1 \mathrm{H}), 8.04(\mathrm{~d}, J=8.8 \mathrm{~Hz}, 1 \mathrm{H}), 7.88(\mathrm{dd}, J=8.1,1.6$ Hz, 1H), 7.74 (ddd, $J=8.4,6.9,1.5 \mathrm{~Hz}, 1 \mathrm{H}), 7.66$ (s, 1H), 7.57$7.49(\mathrm{~m}, 3 \mathrm{H}), 7.25(\mathrm{dd}, J=7.4,1.6 \mathrm{~Hz}, 1 \mathrm{H}), 7.21-7.07(\mathrm{~m}, 4 \mathrm{H})$, 6.72-6.63 (m, 2H), 6.57 (s, 1H), 3.55-3.45 (m, 1H), 3.43-3.28 (m, $1 \mathrm{H}), 1.78-1.63(\mathrm{~m}, 1 \mathrm{H}), 1.62-1.49(\mathrm{~m}, 1 \mathrm{H}), 1.44(\mathrm{~h}, J=7.3 \mathrm{~Hz}$, $2 \mathrm{H}), 0.94(\mathrm{t}, J=7.3 \mathrm{~Hz}, 3 \mathrm{H}) .{ }^{13} \mathrm{C}$ NMR (125 MHz, acetone-d6) $\delta$ 155.95, 148.44, 145.66, 144.60, 136.68, 134.47, 131.35, 130.33, $130.04,129.76,128.85,128.40,128.08,128.00,127.91,127.15$, $127.00,122.76,118.88,116.96,111.46,62.76,49.76,20.85$, 14.24. HRMS (ESI) $\mathrm{m} / z$ calcd for $\mathrm{C}_{28} \mathrm{H}_{27} \mathrm{~N}_{2}{ }^{+}[\mathrm{M}+\mathrm{H}]^{+}: 391.2169$, found: 391.2187 .

$1^{\prime}$-Butyl-2'-phenyl-1', $2^{\prime}$-dihydro-2, $3^{\prime}$-biquinoline $\quad(9) \cdot{ }^{15} \quad{ }^{1} \mathrm{H}$ NMR (400 MHz, acetone- $d 6) \delta 8.01$ (d, $J=8.5 \mathrm{~Hz}, 1 \mathrm{H}), 7.95-7.87$ (m, 2H), 7.78-7.72 (m, 2H), 7.62 (ddd, $J=8.4,6.9,1.5 \mathrm{~Hz}, 1 \mathrm{H})$, 7.51 (dd, $J=8.2,1.4 \mathrm{~Hz}, 2 \mathrm{H}), 7.42-7.31(\mathrm{~m}, 2 \mathrm{H}), 7.21-7.08(\mathrm{~m}$, $4 \mathrm{H}), 7.06-6.97(\mathrm{~m}, 1 \mathrm{H}), 6.94(\mathrm{td}, J=7.4,1.2 \mathrm{~Hz}, 1 \mathrm{H}), 5.90(\mathrm{~s}, 1 \mathrm{H})$, 4.12-3.99 (m, 1H), $3.87(\mathrm{dt}, J=14.8,7.6 \mathrm{~Hz}, 1 \mathrm{H}), 1.91-1.79(\mathrm{~m}$, 2H), 1.63-1.48 (m, 2H), 1.04 (t, $J=7.4 \mathrm{~Hz}, 3 \mathrm{H})$. HRMS (ESI) $\mathrm{m} / \mathrm{z}$ calcd for $\mathrm{C}_{28} \mathrm{H}_{27} \mathrm{~N}_{2}^{+}[\mathrm{M}+\mathrm{H}]^{+}$: 391.2169, found: 391.2187.

$1^{\prime}$-Butyl-2'-methyl-1', 2'-dihydro-2,3' $\mathbf{3}^{\prime}$-biquinoline

(10). Synthesized using a reported procedure. ${ }^{15}{ }^{1} \mathrm{H}$ NMR $(400 \mathrm{MHz}$, acetone-d6) $\delta 8.14(\mathrm{~d}, J=8.9 \mathrm{~Hz}, 1 \mathrm{H}), 7.92(\mathrm{~d}, J=8.8 \mathrm{~Hz}, 1 \mathrm{H})$, 7.87 (d, $J=8.6 \mathrm{~Hz}, 1 \mathrm{H}), 7.77$ (d, $J=6.7 \mathrm{~Hz}, 1 \mathrm{H}), 7.60$ (ddd, $J=$ 8.7, 7.2, 1.7 Hz, 1H), 7.41 (ddd, $J=8.6,7.1,1.1 \mathrm{~Hz}, 1 \mathrm{H}), 7.36$ (s, $1 \mathrm{H}), 7.08-6.96(\mathrm{~m}, 2 \mathrm{H}), 6.57(\mathrm{~d}, J=8.2 \mathrm{~Hz}, 1 \mathrm{H}), 6.49(\mathrm{td}, J=7.3$, $1.0 \mathrm{~Hz}, 1 \mathrm{H}), 5.25(\mathrm{q}, J=6.2 \mathrm{~Hz}, 1 \mathrm{H}), 3.54-3.43(\mathrm{~m}, 1 \mathrm{H}), 3.29-3.11$ (m, 1H), 1.63-1.53 (m, 2H), 1.38-1.27 (m, 2H), 1.06 (d, $J=6.3$ $\mathrm{Hz}, 3 \mathrm{H}$ ), $0.83(\mathrm{t}, J=7.4 \mathrm{~Hz}, 3 \mathrm{H}$ ). HRMS (ESI) $\mathrm{m} / \mathrm{z}$ calcd for $\mathrm{C}_{23} \mathrm{H}_{24} \mathrm{~N}_{2}^{+}[\mathrm{M}]^{+}$: 328.1939, found: 328.1873.

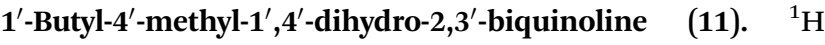
NMR (400 MHz, acetone- $d 6) \delta 7.92(\mathrm{~d}, J=9.0 \mathrm{~Hz}, 1 \mathrm{H}), 7.77$ (dd, $J$ $=8.3,1.0 \mathrm{~Hz}, 1 \mathrm{H}), 7.69-7.61(\mathrm{~m}, 2 \mathrm{H}), 7.50$ (ddd, $J=8.4,6.9,1.5$ $\mathrm{Hz}, 1 \mathrm{H}$ ), 7.47 (s, 1H), 7.26 (ddd, $J=8.1,6.9,1.2 \mathrm{~Hz}, 1 \mathrm{H}), 7.15$ (dd, $J=7.4,1.6 \mathrm{~Hz}, 1 \mathrm{H}$ ), 7.04 (ddd, $J=8.6,7.3,1.6 \mathrm{~Hz}, 1 \mathrm{H}), 6.91-$ $6.80(\mathrm{~m}, 2 \mathrm{H}), 4.52$ (q, $J=6.8 \mathrm{~Hz}, 1 \mathrm{H}), 3.87-3.76(\mathrm{~m}, 1 \mathrm{H}), 3.62$ (ddd, $J=14.8,8.2,7.0 \mathrm{~Hz}, 1 \mathrm{H}), 1.72-1.56(\mathrm{~m}, 2 \mathrm{H}), 1.40-1.29(\mathrm{~m}$, $2 \mathrm{H}), 1.15$ (d, $J=6.8 \mathrm{~Hz}, 3 \mathrm{H}), 0.86(\mathrm{t}, J=7.4 \mathrm{~Hz}, 3 \mathrm{H}) .{ }^{13} \mathrm{C} \mathrm{NMR}$ 
(125 MHz, acetone- $d 6) \delta 155.79,148.80,145.19,136.74,136.10$, 130.87, 130.32, 130.12, 129.54, 128.46, 127.94, 126.91, 126.79, 123.49, 118.66, 116.98, 112.44, 54.67, 49.54, 30.92, 20.92, 17.54, 14.28. HRMS (ESI) $\mathrm{m} / z$ calcd for $\mathrm{C}_{23} \mathrm{H}_{25} \mathrm{~N}_{2}{ }^{+}[\mathrm{M}+\mathrm{H}]^{+}: 329.2012$, found: 329.1991.

2-(1-butyl-1H-indol-3-yl)quinoline (12). Synthesized using a reported procedure. ${ }^{16}{ }^{1} \mathrm{H} \mathrm{NMR}(400 \mathrm{MHz}$, chloroform- $d$ ) $\delta$ 8.87$8.58(\mathrm{~m}, 1 \mathrm{H}), 8.17(\mathrm{dd}, J=8.3,1.1 \mathrm{~Hz}, 1 \mathrm{H}), 8.14(\mathrm{~d}, J=8.5 \mathrm{~Hz}$, $1 \mathrm{H}), 7.87$ (s, 1H), 7.85 (d, $J=8.6 \mathrm{~Hz}, 1 \mathrm{H}), 7.79(\mathrm{dd}, J=8.1,1.4$ $\mathrm{Hz}, 1 \mathrm{H}$ ), 7.71 (ddd, $J=8.4,6.9,1.5 \mathrm{~Hz}, 1 \mathrm{H}), 7.51-7.47(\mathrm{~m}, 1 \mathrm{H})$, 7.47-7.41 (m, 1H), 7.37-7.31 (m, 2H), $4.24(\mathrm{t}, J=7.1 \mathrm{~Hz}, 2 \mathrm{H})$, 2.01-1.87 (m, 2H), 1.53-1.36 (m, 2H), $1.00(\mathrm{t}, J=7.4 \mathrm{~Hz}, 3 \mathrm{H})$. HRMS (ESI) $m / z$ calcd for $\mathrm{C}_{21} \mathrm{H}_{21} \mathrm{~N}_{2}{ }^{+}[\mathrm{M}+\mathrm{H}]^{+}: 301.1699$, found: 301.1704 .

10-Butylacridin-9(10H)-one (15). Synthesized using reported procedure. ${ }^{17}{ }^{1} \mathrm{H}$ NMR (400 MHz, chloroform- $d$ ) $\delta 8.61$ (dd, $J=$ 8.0, 1.7 Hz, 2H), 7.75 (ddd, $J=8.7,7.0,1.7 \mathrm{~Hz}, 2 \mathrm{H}), 7.52$ (d, $J=$ $8.7 \mathrm{~Hz}, 2 \mathrm{H}), 7.36-7.27(\mathrm{~m}, 2 \mathrm{H}), 4.45-4.22(\mathrm{~m}, 2 \mathrm{H}), 2.01-1.88(\mathrm{~m}$, $2 \mathrm{H}), 1.62(\mathrm{~h}, J=7.4 \mathrm{~Hz}, 2 \mathrm{H}), 1.11$ (t, $J=7.4 \mathrm{~Hz}, 3 \mathrm{H}) .{ }^{13} \mathrm{C} \mathrm{NMR}$ (100 MHz, CDCl3) $\delta$ 177.98, 141.82, 133.85, 128.01, 122.52, 121.18, 114.55, 45.98, 29.23, 20.20, 13.86. HRMS (ESI) $\mathrm{m} / \mathrm{z}$ calcd for $\mathrm{C}_{17} \mathrm{H}_{18} \mathrm{NO}^{+}[\mathrm{M}+\mathrm{H}]^{+}$: 252.1383, found: 252.1380 .

\section{Antibacterial activity}

Bacterial strains, plasmids, and growth conditions. The bacterial strains and plasmids used in this study were described previously. Briefly, strain SME4382 carries a single-copy virBlac $Z$ reporter fusion in the chromosome and a plasmid pHG165virF, expressing VirF protein. A control strain SME3359 carries a $l a c Z$ reporter gene under the control of a synthetic promoter that is repressed by LacI, and a plasmid that expresses LacI protein. The bacterial cultures for in vivo dose-response assays were grown in 3 -( $N$-morpholino)propanesulfonic acid (MOPS)-buffered minimal medium. Cultures for growth rate experiments were grown in tryptone-yeast extract (TY) broth (0.8\% Difco tryptone, $0.5 \%$ Difco yeast extract, and $0.5 \% \mathrm{NaCl}$

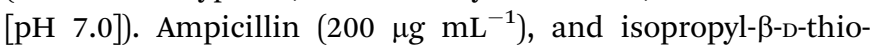
galactopyranoside (IPTG) were added as indicated. All cultures were grown at $37^{\circ} \mathrm{C}$ with aeration, unless otherwise noted.

In vivo dose-response experiments. Twenty-four commercially available compounds were obtained from Sigma Aldrich (St. Louis, MO). In vivo dose-response assays were performed as previously described. ${ }^{12}$ In brief, each analogue was dissolved in $100 \%$ dimethyl sulfoxide (DMSO). Bacterial cultures of SME4382 and SME3359 were grown to an optical density at 600 $\mathrm{nm}$ (OD600) of $\sim 0.1$ and then mixed with various concentrations of analogues (final concentration of DMSO, 6.2\%), induced with $1 \mathrm{mM}$ IPTG (final concentration) for 3 hours at 37 ${ }^{\circ} \mathrm{C}$, lysed, and $\beta$-galactosidase activity was measured. Uninduced (no IPTG and no analogues) and uninhibited (1 mM IPTG and no analogues) controls were included for each of the virBlac $Z$ and control strain, and used to normalize $\beta$-galactosidase activity, as described previously. Fifty percent inhibitory concentrations (IC50) were calculated and graphs were drawn using Graphpad Prism (GraphPad, La Jolla, CA). All data plotted were from three independent experiments with two replicates in each experiment.

$\boldsymbol{E}$. coli growth experiments. To test whether the compounds in this study had any impact on the growth of the bacterial strains used for in vivo dose-response assays (SME4382 and SME3359), the growth rate in the presence and absence of the compounds were compared using a procedure described previously, except the bacterial cultures were grown in TY broth. Briefly, the cells were grown at $37{ }^{\circ} \mathrm{C}$ in TY broth plus $1 \mathrm{mM}$ IPTG (final concentration), in 24-well microtiter plate, either with compounds ( $44 \mu \mathrm{M}, 6.2 \%$ DMSO) or with DMSO $(6.2 \%)$ alone, in a PowerWave XS plate reader (BioTek Instruments).

Stability analysis. Compounds were dissolved at $10 \mu \mathrm{M}$ in PBS at pH 7.4 (1\% DMSO) and incubated at room temperature with either no thiol source as a negative control, $50 \mu \mathrm{M}$ glutathione (GSH). The mixtures were sampled every hour for eight hours or every 8 hours for 48 hours and analyzed by RP HPLC/ UV/HRMS. The analytical RP HPLCUV/HRMS system utilized for the analysis was a Waters Acquity system with UV-detection and mass-detection (Waters LCT Premier). The analytical method conditions included a Waters Acquity HSS T3 C18 column $(2.1 \times 50 \mathrm{~mm}, 1.8 \mu \mathrm{m})$ and elution with a linear gradient of $99 \%$ water to $100 \% \mathrm{CH}_{3} \mathrm{CN}$ at $0.6 \mathrm{~mL} \mathrm{~min}^{-1}$ flow rate. Peaks on the $214 \mathrm{~nm}$ chromatographs were integrated using the Waters OpenLynx software. Absolute areas under the curve were compared at each time point to determine relative percent compound remaining. The masses of potential adducts were searched for in the final samples to determine if any detectable adduct formed. All samples were prepared in duplicate. Ethacrynic acid, a known Michael acceptor, was used as a positive control and was tested in both PBS and PBS/ acetonitrile (1/1).

\section{Acknowledgements}

Research reported in this publication was supported by two Institutional Development Awards (IDeA) from the National Institute of General Medical Sciences of the National Institutes of Health (8P30GM103495 and P30GM103326, SME) and the NIH University of Kansas Chemical Methodology and Library Development Center funded by the NIH Institute of General Medical Sciences (P50GM069663).

\section{References and notes}

1 Organization, W. H. Antimicrobial Resistance: Global Report on Surveillance 2014, 2014, pp. 1-257, http://apps.who.int/ iris/bitstream/10665/112642/1/9789241564748_eng.pdf? $\mathrm{ua}=1$.

2 (a) J. Davies and D. Davies, Origins and evolution of antibiotic resistance, Microbiol. Mol. Biol. Rev., 2010, 74(3), 417-433; (b) K. Bush, P. Courvalin, G. Dantas, J. Davies, B. Eisenstein, P. Huovinen, G. A. Jacoby, R. Kishony, B. N. Kreiswirth and E. Kutter, Tackling antibiotic resistance, Nat. Rev. Microbiol., 2011, 9(12), 894-896; (c) B. K. English and A. H. Gaur, The use and abuse of antibiotics and the development of antibiotic resistance. In 
Hot Topics in Infection and Immunity in Children VI, Springer, 2010, pp. 73-82; (d) H. Madhavan and S. Murali, Mechanisms of Development of Antibiotic Resistance in Bacteria Among Clinical Specimens, J. Clin. Biomed. Sci., 2011, 1(2), 43; (e) B. Spellberg, J. G. Bartlett and D. N. Gilbert, The future of antibiotics and resistance, $N$. Engl. J. Med., 2013, 368(4), 299-302; (f) D. I. Andersson and D. Hughes, Persistence of antibiotic resistance in bacterial populations, FEMS Microbiol. Rev., 2011, 35(5), 901-911; $(g)$ D. M. Shlaes, D. Sahm, C. Opiela and B. Spellberg, The FDA Reboot of Antibiotic Development, Antimicrob. Agents Chemother., 2013, 57(10), 4605-4607; (h) D. Jabes, The antibiotic R\&D pipeline: an update, Curr. Opin. Microbiol., 2011, 14(5), 564-569.

3 D. Higgins, E. Nazareno and V. DiRita, The virulence gene activator ToxT from Vibrio cholerae is a member of the AraC family of transcriptional activators, J. Bacteriol., 1992, 174(21), 6974-6980.

4 O. G. Gómez-Duarte and J. B. Kaper, A plasmid-encoded regulatory region activates chromosomal eaeA expression in enteropathogenic Escherichia coli, Infect. Immun., 1995, 63(5), 1767-1776.

5 A. K. Hovey and D. W. Frank, Analyses of the DNA-binding and transcriptional activation properties of ExsA, the transcriptional activator of the Pseudomonas aeruginosa exoenzyme S regulon, J. Bacteriol., 1995, 177(15), 4427-4436.

6 S. M. Egan, Growing repertoire of AraC/XylS activators, J. Bacteriol., 2002, 184(20), 5529-5532.

7 J. Yang, M. Tauschek and R. M. Robins-Browne, Control of bacterial virulence by AraC-like regulators that respond to chemical signals, Trends Microbiol., 2011, 19(3), 128-135.

8 L. K. Garrity-Ryan, O. K. Kim, J.-M. Balada-Llasat, V. J. Bartlett, A. K. Verma, M. L. Fisher, C. Castillo, W. Songsungthong, S. K. Tanaka and S. B. Levy, Small molecule inhibitors of LcrF, a Yersinia pseudotuberculosis transcription factor, attenuate virulence and limit infection in a murine pneumonia model, Infect. Immun., 2010, 78(11), 4683-4690.

9 A. V. Jennison and N. K. Verma, Shigella flexneri infection: pathogenesis and vaccine development, FEMS Microbiol. Rev., 2004, 28(1), 43-58.

10 S. K. Niyogi, Shigellosis, J. Microbiol., 2005, 43(2), 133-143.

11 J. Mounier, T. Vasselon, R. Hellio, M. Lesourd and P. Sansonetti, Shigella flexneri enters human colonic Caco-
2 epithelial cells through the basolateral pole, Infect. Immun., 1992, 60(1), 237-248.

12 (a) V. Koppolu, I. Osaka, J. M. Skredenske, B. Kettle, P. S. Hefty, J. Li and S. M. Egan, Small-Molecule Inhibitor of the Shigella flexneri Master Virulence Regulator VirF, Infect. Immun., 2013, 81(11), 4220-4231; (b) J. M. Skredenske, V. Koppolu, A. Kolin, J. Deng, B. Kettle, B. Taylor and S. M. Egan, Identification of a SmallMolecule Inhibitor of Bacterial AraC Family Activators, $J$. Biomol. Screening, 2013, 18(5), 588-598.

13 (a) A. Aksenov, O. Nadein, I. Borovlev and Y. I. Smushkevich, Investigations in the region of $2,3^{\prime}$-biquinolyl 5 . Investigation of the reaction of stabilized C-nucleophiles with 1-alkyl-3-(2-quinolyl)-quinolinium halides, Chem. Heterocycl. Compd., 1998, 34(9), 1045-1049; (b) A. Aksenov, Investigations on 2,3'-Biquinolyls. 15. Regioselectivity of the Addition of Nitromethane Anion to $1^{\prime}$-Alkyl-3'(2-quinolyl) quinolinium Halides, Chem. Heterocycl. Compd., 2003, 39(6), 756-759.

14 (a) P. Renton-Harper, M. Addy, J. Moran, F. Doherty and R. Newcombe, A comparison of chlorhexidine, cetylpyridinium chloride, triclosan, and C31G mouthrinse products for plaque inhibition, J. Periodontol., 1996, 67(5), 486-489; $(b)$ N. Bodor and P. Buchwald, Soft drug design: general principles and recent applications, Med. Res. Rev., 2000, 20(1), 58-101; (c) N. Bodor, J. J. Kaminski and S. Selk, Soft drugs. 1. Labile quaternary ammonium salts as soft antimicrobials, J. Med. Chem., 1980, 23(5), 469-474.

15 A. V. Aksenov and O. N. Nadein, Investigation of 2,3'Biquinolyl. 10. The Regioselectivity of the Reaction of $2,3^{\prime}-$ Biquinolyl and 1'-Alkyl-3-(2-quinolyl)quinolinium Halides with Halo Derivatives in the Presence of Metallic Lithium and Magnesium, Chem. Heterocycl. Compd., 2000, 36(11), 1314-1318.

16 M. Brasse, J. A. Ellman and R. G. Bergman, A facile, metaland solvent-free, autoxidative coupling of quinolines with indoles and pyrroles, Chem. Commun., 2011, 47(17), 50195021.

17 D. Garella, A. Barge, D. Upadhyaya, Z. Rodriguez, G. Palmisano and G. Cravotto, Fast, Solvent-Free, Microwave-Promoted Friedländer Annulation with a Reusable Solid Catalyst, Synth. Commun., 2009, 40(1), 120128. 